DOI: 10.11606/issn.2318-8855.v6i6p263-282

\title{
O tempo em Night Journey de Martha Graham ${ }^{1}$
}

Maria Clara Laet de Almeida e Silva*

Resumo: Night Journey é uma coreografia de 1947 da dançarina e coreógrafa estadunidense Martha Graham que foi registrada em forma de filme em 1961. A obra recria a tragédia grega Édipo Rei, de Sófocles, e é situada no momento em que Jocasta, mãe e esposa de Édipo, contempla o suicídio. Através de um flashback, Jocasta, interpretada pela própria Graham, revive sua relação incestuosa antes de tirar sua vida. Conhecida por ser uma das melhores composições da fase mitológica de Graham, Night Journey foi filmada em 1961, permitindo sua análise e estudo até os dias de hoje, além de ser remontada com frequência pela Martha Graham Dance Company. Além de incorporar estruturas de tempo típicas da Grécia Antiga e das tragédias gregas, a coreografia revela vicissitudes do contexto histórico em que foi produzida, possuindo portanto múltiplos estratos de tempo. Aqui se investigará como são estruturadas e como se relacionam estas camadas de tempo, analisando a obra sob a luz de uma História Social do Tempo.

Palavras-Chave: História social do tempo; Martha Graham; Night Journey; Édipo Rei; história da dança.

\footnotetext{
1 Este artigo é uma versão adaptada do trabalho desenvolvido em 2017 para a disciplina de "História Social do Tempo" ministrada na Universidade de São Paulo pelo Prof. Dr. João Paulo G. Pimenta. Agradeço ele pela oportunidade de desenvolver esta reflexão e pelos comentários e sugestões em versões anteriores do texto. Agradeço também Luis Vieira pela inestimável ajuda e apoio ao longo da escrita do texto.

*Graduanda em História na Universidade de São Paulo. Pesquisadora no Laboratório de Estudos sobre o Brasil e o Sistema Mundial (Labmundi). Contato: maria.laet.silva@usp.br
} 
Night Journey é uma obra coreográfica criada pela norte-americana Martha Graham e estreada em 1947. A coreografia foi filmada catorze anos depois como parte do documentário A Dancer's World, um esforço de preservar o trabalho de Graham no fim de sua carreira, e é remontada pela Martha Graham Dance Company até os dias de hoje. A coreografia será analisada a partir do registro de 1961, que conta com Bertram Ross como Édipo, Paul Taylor como Tirésias e Helen McGehee como líder do coro, todos estes bailarinos que tiveram sua formação baseada no método de Graham, e direção de Alexander Hammid. A trilha sonora foi feita especialmente para a coreografia por William Schuman e é usada novamente na filmagem, assim como o cenário desenhado pelo artista plástico Isamu Noguchi. ${ }^{2} \mathrm{~A}$ coreógrafa apresenta um novo olhar sobre a tragédia grega Édipo Rei, buscando representar a terrível relação incestuosa entre mãe e filho por um ponto de vista feminino. O filme de 1961, segundo o bailarino Bertram Ross, não faz jus ao sucesso que obteve a obra em sua estreia de 1947, que consagrou a coreografia como uma das mais conhecidas de Graham, principalmente por não apresentar cores e apresentar contraste muito forte entre o preto e o branco na imagem (FRANKO, 2012, pp. 97 e 199).

Édipo Rei é uma peça escrita por Sófocles e consiste na história de Édipo, o rei de Tebas, que descobre através de uma profecia e um adivinho cego chamado Tirésias que sua esposa é, na verdade, sua mãe, e que o assassino de seu pai era ele mesmo. Ao ver-se envolvido em tal relação, o rei fere seus olhos, fica cego e se exila do reino. A abordagem de Graham concentra-se na figura de Jocasta, a mãe e esposa de Édipo, mais especificamente no momento em que comete suicídio. São colocados em cena elementos que evocam as leituras clássicas da tragédia, como o incesto e a sexualidade, assim como outros não tão presentes na obra original, como o tormento sob a perspectiva de Jocasta.

A abordagem desenvolvida neste artigo explora diversos tempos históricos presentes nesta obra de dança, buscando os significados que estes podem ter para a sociedade 
ocidental. Para tal será considerada a obra como um todo, seus elementos cênicos, figurino, cenário e coreografia, como observados no documentário de 1961.

Primeiramente será observado como a narrativa se estrutura com uma breve apresentação e interpretação das cenas. O ato pode ser dividido em três partes. Na primeira cena Jocasta, interpretada pela própria Graham, fita uma corda enlaçada em forma de forca, segurando-a sobre sua cabeça em um devaneio. Tirésias, o cego adivinho, entra em cena e desfaz o devaneio, provocando um flashback onde Jocasta revive seus momentos de pavor e tormenta. Então, a performance volta ao momento inicial da narrativa original, onde Édipo e Jocasta vivem sua relação amorosa e esta é coroada rainha.

A segunda parte consiste da relação consumada pelo rei e a rainha. Os dois são envolvidos em um jogo de sedução onde um convida o outro por meio de movimentos sugestivos. À medida que vão se aproximando começam a executar movimentos iguais, interrompidos por um devaneio de Jocasta seguido de um movimento maternal executado por ela, levando a cabeça de Édipo ao seu colo. Ao nosso ver, apresenta-se aqui uma ruptura no andamento sensualizado dos movimentos, prenunciando a descoberta do real caráter da relação e do tormento que cairá sobre o casal.

A terceira e última parte é marcada pela intensificação da trilha sonora, com presença dos instrumentos de corda, os sons graves do piano combinados com os violinos extremamente agudos e a aceleração do pulso da música. É caracterizada também pela reaparição do coro anunciando a chegada da tragédia e pelos movimentos mais agressivos entre Édipo e Jocasta envolvendo a mesma corda presente no início da performance. Na cena final, Tirésias desfaz o laço que envolve o casal, Édipo utiliza a joia de Jocasta para cegar-se e a rainha, reencontrando seu destino, despe-se e tira a própria vida.

Night Journey faz parte da fase mitológica da produção de Graham. Nela, as coreografias eram geralmente baseadas ou faziam referência a mitos e tragédias gregas. O surgimento das tragédias gregas se deu na passagem do século $\mathrm{VI}$ ao $\mathrm{V}$ a.C., momento de aparecimento de 


\section{dossiê}

Maria Clara Laet de Almeida e Silva

dois aspectos singulares na cultura grega. Com o advento da historiografia passou-se a empregar uma reflexão mais detalhada sobre os acontecimentos passados. Logo, houve uma maior consciência sobre o passado e a passagem do tempo, fator de peso nas tragédias gregas, que dão papel importante ao passado em suas narrativas. O segundo aspecto é a tensão entre o passado heroico e mítico e o presente com o advento do direito nas póleis gregas. O pensamento jurídico, segundo o helenista Jean Pierre Vernant, traz ao centro das discussões a inserção do cidadão na coletividade da pólis. Esta vida consumada no âmbito da coletividade da pólis, baseada nas discussões políticas, jurídicas e na cidadania, contrasta com o passado que se encontra no âmbito individual e singular representado pela ação de heróis gregos singulares, produzindo assim uma tensão entre passado e presente. Assim, estes dois aspectos se relacionam, uma vez que tal tensão produz distanciamento entre estes dois tempos, permitindo que se possa pensar a passagem do tempo e elaborar sobre o passado, construindo então o que chamamos hoje de historiografia. (VERNANT, 1999)

De um lado, o elemento humano e coletivo do cidadão; de outro, o elemento divino e singular dos heróis e mitos. De um lado, o presente na cidade; do outro, o passado mítico. Contudo, o advento da historiografia grega, representada por Tucídides e Heródoto principalmente, teve lugar depois da escrita de Édipo Rei por Sófocles, portanto esta tensão entre passado e presente não está presente na tragédia de Sófocles. Ainda assim, é possível observar tal tensão na reinterpretação de Graham. O coro, chamado pela coreógrafa de Daughters of the Night, representa o presente, é ele quem julga e sabe a verdade e o decurso dos acontecimentos. Segundo Mark Franko (2012), Graham, em suas anotações feitas em vida nos famosos Notebooks, fez esta assertiva, que faz sentido coreograficamente. O coro, sendo a consciência de Jocasta no momento de sua morte, está em cena ao mesmo tempo em que é consumado o amor entre ela e seu filho, na terceira parte da coreografia. Com isso, o presente em que Jocasta sabe da verdadeira identidade de seu esposo coexiste com seu passado, sendo relembrado e iluminado por esta consciência que, desesperada, anuncia a tragédia no primeiro plano do palco. Com movimentos frenéticos e bruscos, o coro contrasta 
com a memória cinzenta e embaçada do passado, sendo encenado no fundo do palco por movimentos lentos e contínuos (FRANKO, 2012, p. 107). A trilha sonora de William Schuman é outro elemento que denota o confronto entre estes dois tempos, alternando entre notas suaves e agudas e notas rápidas, graves e intensas.

Segundo Mark Franko, o trabalho de Graham pode ser dividido em três fases: a primitivista (1926-1933), a dramatúrgica (1934-1945) e a mitológica (de 1945 em diante) (FRANKO, 2012, pp. 7-8). É possível perceber o predomínio da influência da primeira fase sobre as coreografias de outras fases e a presença desta volta ao passado em outras narrativas como Deaths and Entrances (1943), que conta também com a utilização do recurso d e flashback. A busca por elementos primitivos, algo próprio da dança e das artes das décadas de 1920 e 1930, é característica própria do movimento artístico nos Estados Unidos denominado modernismo. O modernismo tratado aqui pode ser considerado um conjunto de ideias e pensamentos que se manifestaram nas artes que surgiram em resposta à modernização do século XX. Tal resposta consistiu, no caso do modernismo norte-americano, em um retorno à natureza do homem e sua subjetividade (SINGAL, 1987, pp. 7-8). Nas artes plásticas observou-se um movimento de volta ao passado em busca de características essenciais da natureza humana como um meio de buscar tal subjetividade (POLCARI, 1990). O retorno ao passado em busca de elementos ancestrais, míticos e rituais permanece como uma forte característica do trabalho de Graham, como pode ser observado neste comentário em sua autobiografia:

There are always ancestral footsteps behind me, pushing me, when I am creating a new dance, and gestures are flowing through me. Whether good or bad, they are ancestral. You get to the point where your body is something else and it takes on a world of cultures from the past, an idea that is very hard to express in words (GRAHAM, 1991, p. 13)

Graham é considerada uma das precursoras de um novo estilo de dança denominado modern dance. Com a descentralização do ballet clássico, novas técnicas e maneiras de se ver a dança suscitam em um mundo fragmentado pela aceleração do tempo. O etéreo dá lugar ao a movimentos próximos ao chão; o corpo longilíneo ao contraído; as figuras elegantes a 
dançarinos musculosos; a fluidez aos espasmos e ângulos austeros. O que em Isadora Duncan, uma das primeiras a fugir da rigidez da técnica clássica, era leve e divertido, cada vez mais tornou-se demarcado e contraído (SOUZA, 2009, pp. 94-135). Os grandes nomes que marcaram esta tendência foram Ruth St. Denis e Ted Shawn, que fundaram a Denishawn, escola de dança que ficou marcada pela produção de grandes talentos como Martha Graham (AU, 1995, p. 119). Assim, a tensão entre passado e presente está manifesto na própria vida pessoal da coreógrafa: sua saída da Denishawn deveu-se a uma busca de seu próprio estilo, busca manifesta na criação de sua própria técnica, baseada na contração e expansão a partir do abdômen.

Em Night Journey é manifesta a busca de Graham por um passado "primitivo" longínquo em diversos aspectos, elemento expresso no enredo de Night Journey: o mito de Édipo. Este primitivismo do modernismo norte-americano anseia por uma ideia de passado longínquo criada pelo século XIX, que romantizou e idealizou a Grécia Antiga, considerada pela história positivista e clássica como o berço da civilização ocidental (SEIGNOBOS, 1915, p. 223), um lugar e uma cultura ancestral no sentido mais latente da palavra: como um passado hereditário. Este passado, louvável, contrasta com a efemeridade da modernidade presenciada por Graham. Édipo Rei representa este resgate do passado como origem, objeto de estudo para entender um presente volátil e difícil de decifrar. Foi também estudada por Freud a fim de investigar impulsos universais e primitivos de todo o ser humano (ELIADE, 1972, p. 57). Assim, este movimento manifesta-se coreograficamente: a despreocupação de Graham com a estética leve do balé clássico, ofloor work, a ligação com o chão e os movimentos pesados evidenciam o impulso primitivo do qual fala em sua autobiografia. Sua técnica, baseada em espasmos, na respiração, contração e expansão do torso, remete não só aos fazeres primitivos do corpo como a própria respiração como também ao tempo cíclico e biológico do corpo humano: inspirar e expirar, expandir e contrair (SOUZA, 2009, pp. 117132). 


\section{dossiê}

O tempo em Night Journey de Martha Graham

Assim, a obra apresenta também uma temporalidade circular, presente não só na técnica grahamiana como na estrutura da coreografia. A narrativa começa e termina no mesmo lugar: na morte da personagem principal. É possível relacionar esta circularidade à estrutura dos mitos da Grécia Antiga: o passado mítico grego evoca uma estrutura de eterno retorno e eternidade imóvel que transparece no fato de o início e o final da performance se situarem no mesmo momento. Ainda assim, elementos além da circularidade revelam-se na estrutura da narrativa. De acordo com Pierre Vidal-Naquet, o tempo dos heróis trágicos é o tempo efêmero em contraste com o tempo divino. O tempo efêmero articula-se com a sucessão de acidentes que costuma ocorrer na tragédia: Édipo Rei, por exemplo, ocorre em apenas um dia (VIDAL-NAQUET, 1960). Assim, existe uma transformação que evidencia a construção da narrativa coreográfica em início, meio e fim, uma vez que as cenas do início e do fim são diferentes: há uma linearidade sem a qual o espectador não entenderia a decisão de Jocasta, uma narrativa linear que faz a diferença na percepção da morte da personagem principal. Além de entendermos o motivo da decisão da rainha de terminar a sua vida, a sua vida termina de um jeito diferente do que se esperava. Observa-se que, no início, Jocasta fita uma corda enlaçada em forma de forca; no entanto, acaba por estrangular-se na cena final. Com isso pode-se dizer que a rememoração do passado também transformou a personagem e seu futuro, ainda que de maneira sutil. A transformação pressupõe uma narrativa linear, tanto apontando para o passado, que é evocado em forma de flashback, quanto para o futuro, moldado pelas mudanças da personagem ao longo da trama.

A linearidade está presente em diversos elementos da performance. Observemos o figurino. As mulheres do coro vestem vestidos escuros em contraste com linhas claras na bainha dos vestidos, subindo pelo seu torso. As linhas estão estrategicamente posicionadas, uma vez que a barra dos vestidos acompanha o movimento das bailarinas, dando destaque ao detalhe, que também compõe o figurino de Édipo e Jocasta. O cenário insere-se na mesma concepção estética: os bancos alinhados ao fundo em escala crescente levando à cama dão 


\section{dossiê}

Maria Clara Laet de Almeida e Silva

ênfase especial à cena da ascendência de Édipo ao poder, reforçando o caráter linear da narrativa. Esta cena pode ser observada na imagem 2.

A hereditariedade entre os dois personagens principais também comporta uma concepção de tempo sagital, prenunciada pelos objetos cênicos presentes na segunda parte da performance que se assemelham as videiras. São vários os elementos que remetem ao tempo natural e biológico da vida humana, como a cama feita de ossos e até mesmo a corda com a qual Jocasta se enforca. Esta adquire diversos usos e significado ao longo da narrativa: em sua autobiografia, Graham descreve este objeto como um cordão umbilical, e não à toa a escolha do material para a corda foi a seda. A corda é a linha que liga as duas gerações, é o tempo biológico da vida humana e é o destino de Jocasta.

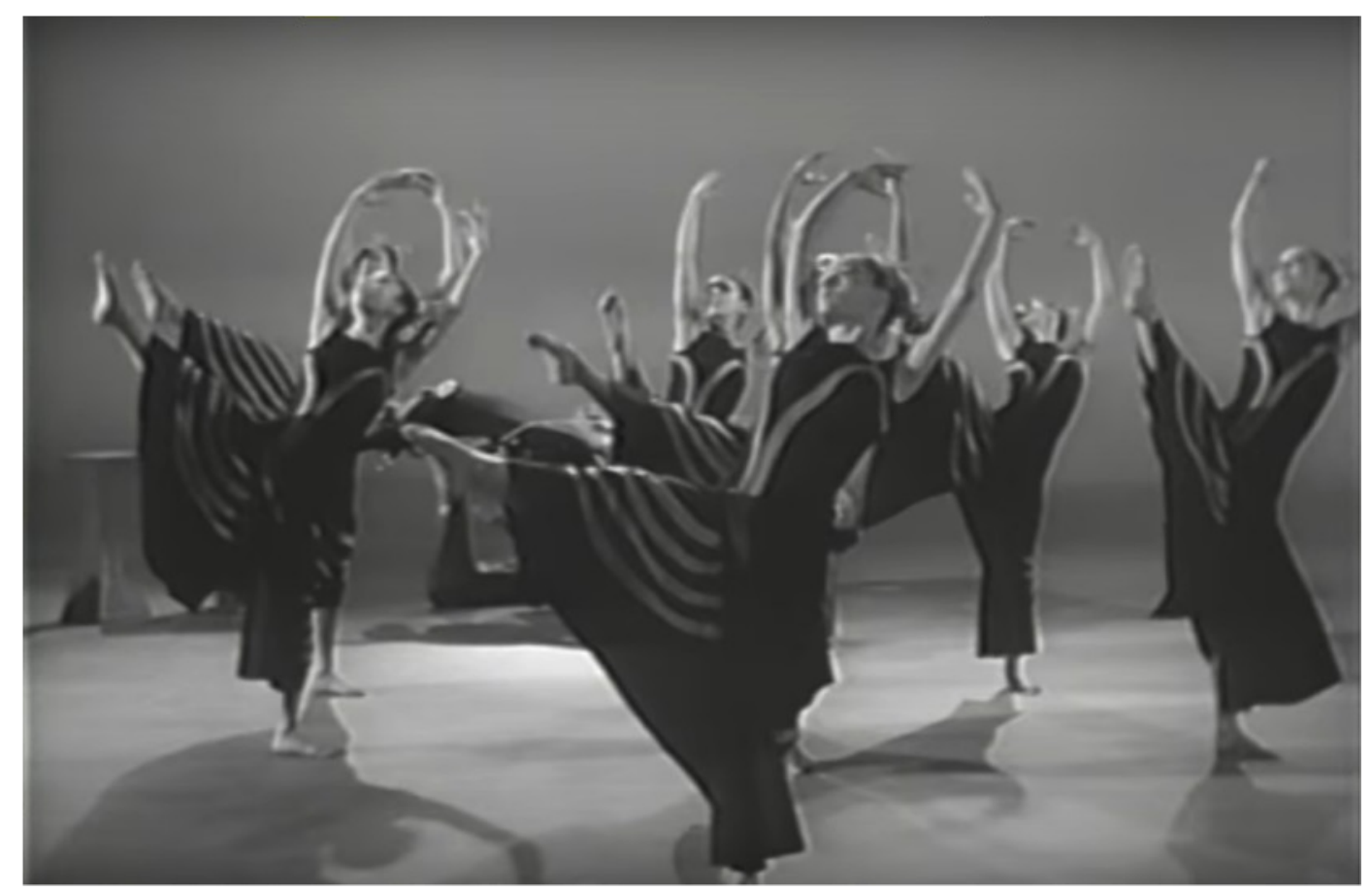

Imagem1: O coro com seu figurino decorado por linhas (HAMMID, 1961). 


\section{dossiê}

O tempo em Night Journey de Martha Graham

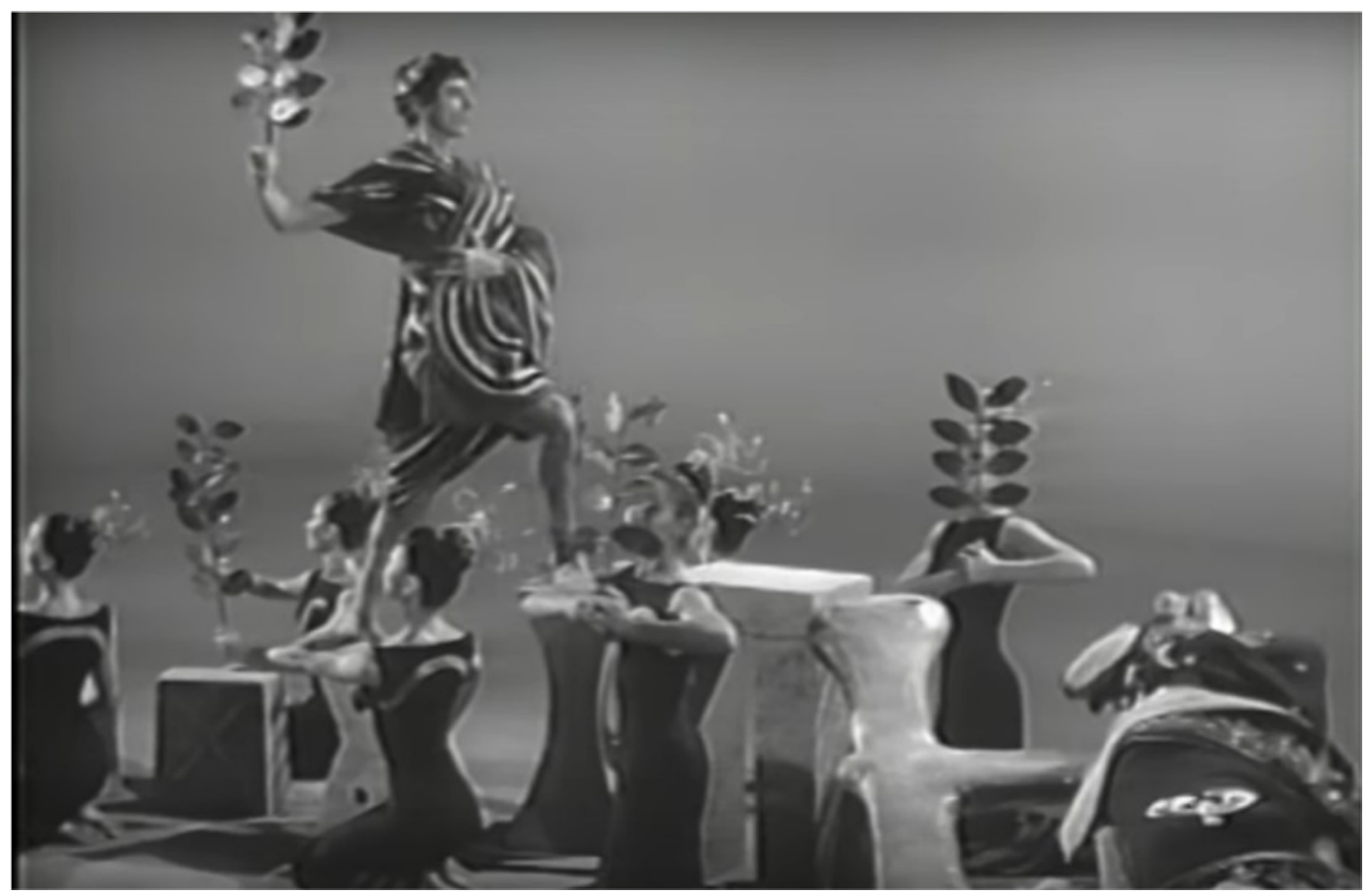

Imagem 2: Os bancos, em ordem de altura crescente, onde Édipo ascende à realeza ao encontro de Jocasta. O coro segura as videiras (HAMMID, 1961).

Este último significado pode ser atrelado ao mito grego das moiras. Estas eram três tecelãs: Cloto, Láquesis e Átropo. A primeira fiava o fio com uma roca, a segunda media o fio com uma vara e a terceira o cortava, dando fim à vida de um mortal (PÉREZ MIRANDA; CARBÓ GARCÍA, 2011, p. 137). As moiras representam a inevitabilidade do destino e como não se pode escapar dele, elemento que está presente em peso no mito de Édipo por este, apesar de tentar, não conseguir fugir do parricídio cometido por ele próprio. O gesto da costura e selamento do destino está principalmente na figura de Tirésias e seu grande bastão cruzando o palco em movimentos de zigue-zague, apoiando o bastão no chão como uma agulha que tece. O bastão de Tirésias possui, na composição, o poder de selar destinos. Isto é perceptível quando usa o bastão para tirar das mãos de Jocasta a forca, induzindo o flashback, quando o bate no chão entre Édipo e Jocasta confirmando sua tormenta, e na cena em que, desesperadamente, Jocasta tenta tomar o bastão de Tirésias, mas não tem poder sobre seu próprio fim. O coro, nas duas vezes em que entra em cena, anuncia o futuro com movimentos 
espasmódicos e frenéticos, sabendo que não tem poder sobre a tragédia que está por acontecer.

Esta atribuição ao elemento cênico evoca o tempo circular, determinado, fechado em sua eternidade e onde os homens não possuem poder sobre seu destino, defendida, dentre muitos outros, pelos estoicos na Grécia. Segundo Whitrow, para eles, o Destino tinha um caráter cíclico, ou eternamente recorrente. Identificavam-no com a Necessidade e simbolizavam-no pelo incessante girar de uma roda, como a roda de Íxion" (WHITROW, 1993, p. 63). A roda de Íxion é outro mito grego onde Íxion, incapaz de controlar seus desejos, é castigado por Zeus a permanecer no Tártaro preso a uma roda. O desejo sexual pela sua mãe está em Édipo e, curiosamente, o único elemento cênico não utilizado pelos bailarinos é uma roda de proporções grandes, encostada no fundo da cena à direita. Este elemento evidencia ainda mais o conhecimento de Graham da mitologia grega e a presença de regimes de temporalidade próprios da mitologia como a eternidade e a circularidade e pode ser observado na imagem 3.

O tempo circular e o tempo sagital, tanto apontando para o futuro quanto para o passado, coexistem em Night Journey. O suicídio, contemplado no início e realizado no final da peça, é representante de mais uma presença do tempo sagital na narrativa. A morte representa um aspecto do tempo que todo o ser humano deve enfrentar: a finitude. Em História da morte no Ocidente, Philippe Ariès analisa como a sociedade ocidental lidou com a morte ao longo do tempo e chega a quatro tipos de abordagem acerca da percepção da morte na sociedade ocidental que, grosso modo, estabelecem uma periodização. É curioso pensar que, baseando-se na periodização proposta por Ariès, enquanto Sófocles convivia com uma destas atitudes diante da morte, Graham, que usa seu texto, convive com outra. O fato de Sófocles estar situado em um tempo de morte domada, ou seja, em uma sociedade onde a morte era tratada com naturalidade, pode ser uma explicação do porquê a morte de Jocasta não receber tanta atenção no texto. 


\section{dossiê}

O tempo em Night Journey de Martha Graham

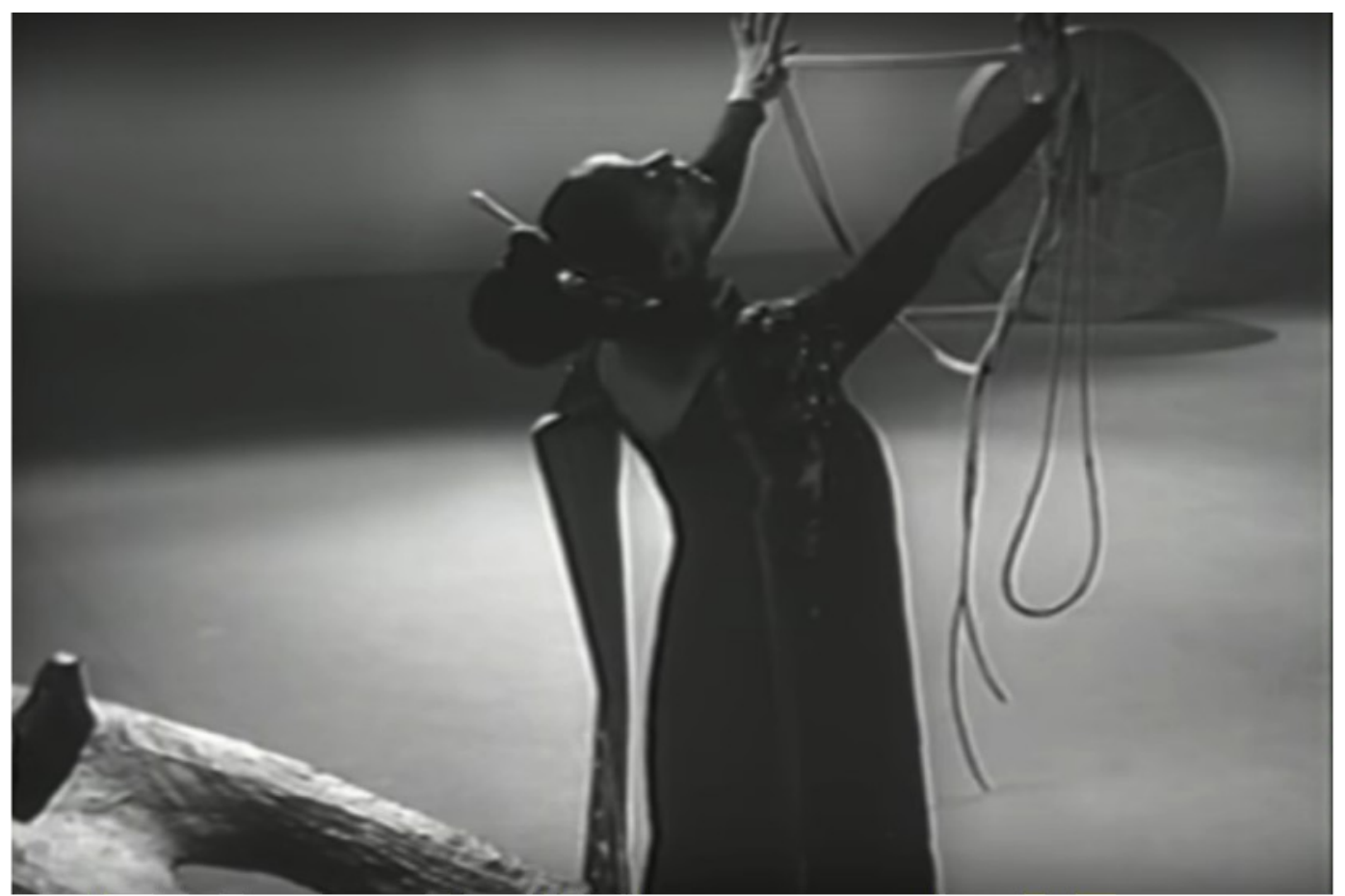

Imagem 3: Jocasta contempla a forca; ao fundo, a roda de Íxion (HAMMID, 1961).

Já Graham coloca neste evento o ponto visceral de sua obra, e isto se enquadra principalmente na noção romântica presente na morte do outro. O espectador desenvolve compaixão pela morte representada em cena em forma de dança, esteticizada, trazendo a noção moderna de uma sociedade que vive o desenraizamento (BERMAN, 1982 e KOSELLECK, 2000). É possível identificar também a morte de si mesmo na composição a partir do recurso do flashback. Isto porque esta atitude perante a morte é individualizada e apresenta, no leito de morte, uma recapitulação da vida do enfermo, trazendo o julgamento de seus atos em vida para o momento de sua morte. O Juízo Final, portanto, é deslocado do fim do mundo para o fim da vida. O flashback traz o elemento de rememoração da vida de Jocasta, que se encontra sozinha no início da performance e sozinha novamente no final. É importante notar que a morte de Jocasta, na peça de Sófocles, não ocorre no final da narrativa, evidenciando a escolha de se colocar o fim da vida de Jocasta como o fim da peça e também o fim da noite, que é o plano de fundo da narrativa. 


\section{dossiê}

Maria Clara Laet de Almeida e Silva

Faz parte da atitude de morte do outro teorizada por Ariès a morte erotizada. Esta ideia especificamente se encaixa tanto em Night Journey quanto na peça de Sófocles. A relação entre a morte e Eros se dá amplamente na poesia e arte gregas. A morte muitas vezes é relacionada à violação sexual, com o retrato de Eros como homicida. A autora Emily Vermeule afirma que o amor e a morte são aspectos do mesmo poder (VERMEULE, 1984, p. 256) e este imperativo é um dos pontos axiais de Night Journey. A corda com a qual se faz o laço entre Édipo e Jocasta é a mesma que executa a morte desta. A tragédia que leva à morte é a relação sexual incestuosa e isto fica claro a partir da movimentação de Jocasta quando se vê afundada em sua agonia: abre e fecha as pernas, põe a mão em seu ventre, anda em círculos estendendo sua perna acima de sua cabeça como que expondo sua genitália. A cama presente no cenário, onde se consuma o ato sexual, comporta morbidez em sua estrutura em formato de ossos, explicitando ainda mais esta relação.

Por fim, cabe uma análise mais detalhada da cena final da performance. O desfecho da narrativa se dá a partir do momento em que Tirésias rompe o laço entre Édipo e Jocasta, tocando seu bastão, investido do poder de trançar destinos, no cordão umbilical que une ambos. Antes disto ocorrer, o casal via-se numa estaticidade diferente do resto da composição. Enquanto o coro, frenético, estava à frente da cena, o rei e a rainha estão em cima da cama, entrelaçados pelo cordão, fazendo poses e movimentando-se lentamente para trocar de uma pose para a outra. As posições lembram estátuas gregas, mas mais do que isso: a estaticidade transmite uma impossibilidade de se ver livre da relação amorosa incestuosa, anunciada pelo coro. A corda os prende a um destino do qual não podem escapar. 


\section{dossiê}

O tempo em Night Journey de Martha Graham

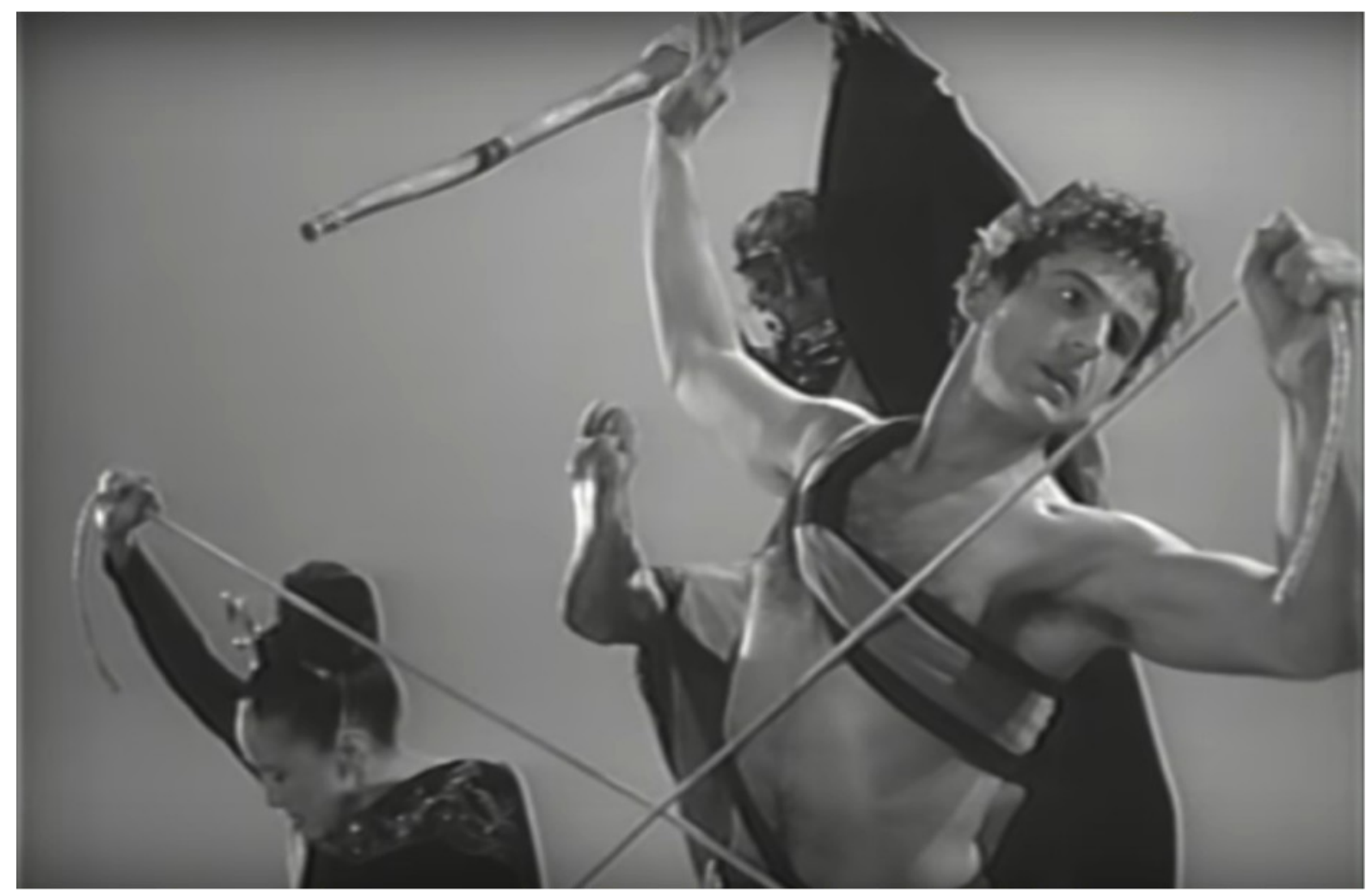

Imagem 4: Momento em que Tirésias rompe o cordão umbilical (HAMMID, 1961).

Então, Tirésias rompe a corda. A tragédia está enfim consumada. Jocasta se estira na cama e Édipo, ainda emaranhado na corda, joga-a no chão com força. O rei, ao invés de ensejar seu fim, quer apenas se ver longe de seu passado. Então tira a joia que a rainha carregava no peito e usa-a para cegar-se. Jocasta, acordando sozinha, avista a corda, despe-se e enforca-se.

Há nesta cena diversos elementos que indicam uma representação do tempo em que Graham vive: a sociedade ocidental em 1947. O caráter explícito e violento da coreografia pode ser visto como manifestação do trauma que viveu o ocidente após as grandes guerras no século XX. Neste momento, discutia-se a ação destrutiva do homem e a banalidade do mal e investigava-se o tema a partir da psicanálise. A psicanálise nas artes como forma de explicar o homem e perscrutar seus impulsos foi um fenômeno forte nos Estados Unidos que 
adentrou a dança, tendo um de seus maiores representantes em Martha Graham. Segundo Stephen Polcari:

As America entered the second great cataclysm of the twentieth century, Graham increasingly moved toward psychological introspection as a subject in her art. In fact, by the time war clouds overshadowed Europe in 1937, she had already stated that for her the goal of dance was to "make visible the interior landscape," and she described her work as "journeying"_ into herself. Dance, in Graham's mind, had the power to move into the "depths of man's inner nature, the unconscious, where memory dwell (POLCARI, 1990, p. 3)

De tal forma, assim como em outros terrenos da arte como o expressionismo abstrato, a psicanálise influenciou profundamente a dança moderna estadunidense, movendo Graham a buscar temas como os mitos e tragédias gregas a fim de explorar os impulsos primitivos e subconscientes do homem. Tal perspectiva ilumina mais uma temporalidade presente em Night Journey: o tempo subjetivo.

O primeiro traço da presença deste tempo está no próprio título da obra. A noite é parte de um ciclo da natureza e, historicamente, é lugar de obscuridade, medo, morte e sensualidade, todos estes elementos explorados pela psicanálise (VERMEULE, 1984, p. 246) É possível analisar Night Journey a partir de arquétipos jungianos de masculinidade e feminilidade. Sabendo que o coro é chamado de Daughters of the Night e são extensão da consciência de Jocasta, é possível concluir que Jocasta é a própria representação da noite. O arquétipo da feminilidade abarca a noite, e o da masculinidade o sol. Sendo a rainha a representação da noite e o rei a do sol é possível, a partir desta análise, observar a manifestação do tempo da natureza, que oferece as experiências temporais iniciais do ser humano, baseadas em ciclos circadianos que regulam a vida humana. Há signos dessa temporalidade nos elementos cênicos, por exemplo na coroa usado por Jocasta em forma de lua e as cores escuras dos figurinos femininos, personalizando a noite. Ademais, é importante ressaltar que a associação entre morte e Eros se dá à noite, intermediada pelo sonho. O sonho, por sua vez, é outro objeto de investigação da psicanálise, e pode ser relacionado à segunda palavra do título da coreografia. Jornada é uma palavra frequentemente empregada 
para descrever o acesso ao subconsciente e a introspecção, ligados ao período da noite pelo sonho. Na coreografia, o público presencia a jornada pelo subconsciente de Jocasta, explorando seu trauma e memória a partir do recurso de flashback.

A presença da psicanálise era evidente no trabalho de Graham ao ponto de suscitar discussões sobre quem a influenciou de forma mais intensa. Filha de psicólogo, a bailarina entrou em contato com as obras de Freud e Jung, fazendo com que a discussão se polarizasse entre aqueles que consideravam Night Journey freudiano e os que consideravam-no junguiano. Como se fazia presente o complexo de Édipo no trabalho de Graham? Era rejeitado ou afirmado? Um elemento que poderia oferecer respostas para estas indagações é o deslocamento do foco da obra de Édipo, figura masculina, para Jocasta, figura feminina. E colocada em evidência a relação de Édipo com sua mãe, e não com seu pai. Tal deslocamento trouxe informação ainda mais valiosa: talvez quem tivesse influenciado Graham não fosse nem Freud e nem Jung, e sim Otto Rank, um psicanalista que relativizava a obra de Freud e grande ídolo do pai de Graham (FRANKO, 2012, p. 128).

Ao investigar o que defendia Otto Rank são iluminados muitos aspectos do tempo subjetivo em Night Journey que são de suma importância. Diz Mark Franko que

Psychoanalysis explains disgust before the representation of incestuous relations as a symptom of repression of the unconscious urges associated with incest. But, according to Otto Rank, the artist is unique in being able to unlock this repressed material and allow the unconscious some relief from lifelong repression. This is precisely, for Rank, the social function of the artist and why the artist's engagement with incest is a socially positive force (FRANKO, 2012, p. 127)

A implicação desta afirmação é de que a dança, mais do que o teatro ou qualquer outra arte, teria a capacidade de se aprofundar na psyché humana e dessublimar o espectador. É a partir desta chave de interpretação que Graham compõe a coreografia de maneira que quem assistisse não apenas presenciasse a jornada subjetiva de Jocasta e sim fizesse parte dela. A ideia da coreógrafa é de "dessublimar a plateia", integrando-a à temporalidade vivida pela personagem principal. Esta ideia é exposta por meio da construção da narrativa em flashback, 
onde o público emaranha-se na consciência de Jocasta, e também esteticamente. Em Night Journey e na modern dance o corpo é "signo de uma mediação entre o mundo objetivo e subjetivo." (SOUZA, 2009, p. 115).

Foi também Otto Rank que deslocou o eixo do mito de Édipo do filho para a mãe, dando um enfoque feminino compatível com o examinado na coreografia. Há uma clivagem na experiência do tempo masculina e feminina dentro da obra. Ramsay Burt diferencia o tempo masculino e feminino a partir da movimentação das personagens pelo espaço (BURT, 1998, p. 49). Ele diferencia o tempo linear vivido por Édipo, obedecendo a ordem cronológica da narrativa que começa com sua coroação e termina com sua cegueira e exílio, e a experiência circular de tempo de Jocasta, que rememora sua vida, começando e terminando a performance na mesma cena. Tirésias também é englobado na percepção linear e masculina: entra em cena sempre pela diagonal esquerda e percorre todo o palco, ensejando um tempo linear vivido por ele. Já Jocasta começa e termina em cena, sem nunca sair, expondo sua ligação com o tempo circular.

O tempo cíclico ligado à feminilidade pode relacionar-se, ainda, ao tempo cíclico que o corpo feminino vive, tempo este que justamente permite a criação da vida, que no caso de Jocasta foi determinante não para efetivamente criar vida e sim para engendrar sua morte. Todos estes tempos históricos estão inseridos no tempo natural, nos ciclos do corpo humano, ciclos circadianos e tempos biológicos e da natureza, todos estes complementares entre si.

Mark Franko também comenta a diferença entre as temporalidades masculina e feminina:

Female subjectivity has been identified with two types of time - the monumental (eternal) and the cyclical (repetition and rhythmicity) - and masculine time as cursive, the time of linear history: drama and expression. The monumental and the cyclical are manifest in most of Graham's output (in particular her use of myth and repetition). (FRANKO, 1990, p. 118)

A afirmação de Franko pode ser observada em Night Journey de duas diferentes formas. A primeira é a movimentação e a própria composição coreográfica. Percebe-se que Jocasta e o 
coro, exclusivamente formado por mulheres, executam movimentos circulares e repetitivos. Destacam-se o movimento de abrir e fechar pernas, uma marca registrada da coreógrafa, e o momento em que Jocasta coloca as mãos sobre os seios e a genitália e gira repetidas vezes, na primeira parte da obra. A linearidade do corpo masculino pode ser encontrada na composição principalmente no solo de Édipo, após ser coroado. A extensão da perna para frente e por vezes sobre Jocasta mostra o poder e sedução sobre ela e move Édipo sobre a plateia, fazendo com que, além da sua trajetória, seu corpo projete-se linearmente.

A segunda maneira pela qual se constata a afirmação é pela visão que o bailarino, mais especificamente Martha Graham, tem do próprio corpo. A passagem do tempo biológico tem implicações importantes para a vida do bailarino, uma vez que sua vida profissional depende diretamente da capacidade de seu corpo de executar movimentos complicados e até mesmo perigosos. O tempo biológico e o envelhecimento contrasta com a imagem heroica e mítica construída sobre o bailarino na década de 1940, como é possível examinar no documentário que precede Night Journey em sua versão em filme de $1961 .^{3}$

Enquanto são apresentadas imagens de sua companhia na sala de ensaio, Graham diz que o dançarino não é uma criatura fenomenal, e sim "divine normal", e segue dizendo que são necessários pelo menos dez anos de muita dedicação para alcançar tal estado divinizado do corpo. A palavra "divine" é usada constantemente em sua fala e é reforçado o esforço preciso para ser um bom dançarino profissional. Com isso, é possível reiterar a visão monumental do bailarino da qual comenta Franko, principalmente do corpo feminino.

A dimensão pessoal que Graham traz para a composição é manifesto. As semelhanças entre os personagens recriados e sua vida pessoal mergulha a plateia na temporalidade subjetiva não só de Jocasta mas dela mesma. A autodestruição, signo dos tempos traumáticos depois das guerras do século $X X$, está presente na obra por duas vias: pelo tempo presente em que a obra é composta e pelo tempo subjetivo da vida pessoal da coreógrafa. Esta Jersey. Kultur Dance Series. 1961. Disponível em https://www.youtube.com/watch?v=30Qz etlhtg\&t=1578s Acesso em: 31 dez. de 2017. 
dimensão torna-se clara em uma das últimas cenas: Édipo, ao optar pela cegueira, o faz por querer esquecer seu passado e não viver seus erros. Para tal, usa como instrumento de seu autoflagelo a joia que Jocasta carrega no peito. No documentário A Dancer's World, Graham menciona seu processo de transformação na personagem, o que pode ajudar no desvendamento do que pode representar a joia. Nele, a bailarina conta que, para tornar-se sua personagem, a maquiagem e o figurino são de extrema importância. Diz ainda que, quando Jocasta se reconhece no espelho, ela está pronta para subir ao palco.

Dada a importância do figurino para a coreógrafa, e observada a semelhança que a joia possui com o adereço na cabeça, é possível supor que este elemento seja identitário. O que torna Martha Graham Jocasta depende destes elementos. Então, Édipo, para se cegar, utiliza a razão primeira de seu tormento: a identidade de sua esposa que era, em realidade, sua mãe. Despida de sua identidade, desenraizada e sem perspectiva de futuro, Jocasta então despe-se de seu vestido, outro de seu elemento identitário, e enforca-se, assim como Édipo, com o elemento representante da razão de sua angústia. Esta última cena se mostra um retrato coerente do momento que vive Graham em 1947: naquele momento vivia a autodestruição engendrada pelo homem pelas guerras, além de sua autodestruição iminente com seu relacionamento conturbado. É despida de sua identidade como bailarina pela passagem do tempo biológico e perde, aos poucos, seus status divinizado e atemporal. A modern dance traz, sobretudo, este corpo conflitante, que tem necessidade de se presentificar em um mundo onde o tempo é líquido. Os movimentos súbitos das últimas cenas trazem a instabilidade da modernidade e a esteticidade da modern dance, que consiste em

dedicar-se a uma dimensão da vida social, aos recantos do imaginário, do gesto, do silêncio, dos fluxos respiratórios que há no viver dos que sonhavam, mesmo na adversidade, e num contrato amplo de contradições (SOUZA, 2009, p. 98).

Com isso, é possível afirmar que há diversos tempos sociais vigentes em Night Journey, temporalidades sedimentadas e sobrepostas, cíclicas e lineares, universais e subjetivas, passadas e presentes, que nos dizem muito da ambivalência moderna em que Martha 
Graham monta sua coreografia e dos caminhos cruzados, continuidades e rupturas que se fazem entre múltiplos tempos históricos e o tempo do espectador, que tem acesso ao mito de Édipo em suas diversas formas até os dias de hoje.

\section{Fonte:}

Martha Graham in Performance. Direção: Alexander Hammid. Produção: Nathan Knoll. West Long Branch, New Jersey. Kultur Dance Series. 1961. Disponível em: https://www.youtube.com/watch?v=30Qz_etlhtg\&t=1578s Acesso em: 31 dez. de 2017.

\section{Referências bibliográficas:}

ARIÈS, Philippe. História da morte no ocidente. Rio de Janeiro: Francisco Alves, 1977.

AU, Susan. Ballet \& Modern Dance. New York: Thames and Hudson Inc., 1995

BERMAN, Marshall. Tudo o que é sólido se desmancha no ar. São Paulo: Companhia das Letras, 2007.

BURT, Ramsay. Dance, Gender and Psychoanalysis: Martha Graham's "Night Journey.Dance Research Journal. Vol. 30, No. 1 (Spring, 1998)

ELIADE, Mircea. Mito e realidade. São Paulo: Perspectiva, 1972.

GRAHAM, Martha. Blood Memory. London: Macmillan, 1991

FRANKO, Mark. Dance and the Political: States of Exception. Dance Research Journal, vol. 38, no. 1/2, 2006, pp. 3-18. Disponível em www.jstor.org/stable/20444656. Acessado em $31 / 12 / 2017$.

. Dancing Modernism/Performing Politics. Indiana University Press, 1995.

Emotivist Movement and Histories of Modernism: The Case of Martha Graham. Discourse, vol. 13, no. 1, 1990, pp. 111-128. Disponível em www.jstor.org/stable/41389172. Acessado em $31 / 12 / 2017$.

. Martha Graham in Love and War: The Life in the Work. Oxford and New York: Oxford University Press, 2012.

KOSELLECK, Reinhart. Futuro passado: contribuição à semântica dos tempos históricos. Rio de Janeiro: Contraponto, 2006.

. Estratos do Tempo: estudos sobre história. Rio de Janeiro: Contraponto, 2014.

PÉREZ MIRANDA, Iván; CARBÓ GARCÍA, Juan Ramón, Hijas de la Noche (I): mito, género y nocturnidad en la Grecia antigua, en ARYS, 8, 2009-2010 (2011), pp. 129- 140. 
POLCARI, Stephen. Martha Graham and Abstract Expressionism. Smithsonian Studies in American Art, vol. 4, no. 1, 1990, pp. 3-27. Disponível em www.jstor.org/stable/3108994. Acessado em 31/12/2017.

SEIGNOBOS, Charles. Histoire ancienne: narrative et descriptive de l'orient et de la Grèce. Paris: Armand Colin, 1915.

SINGAL, Daniel Joseph. Towards a Definition of American Modernism. American Quarterly, vol. 39 , no. 1, 1987, pp. 7-26

SOUZA, José Fernando Rodrigues. As Origens da Modern Dance - Uma análise sociológica. São Paulo: Annablume, UCAM, 2009

VERMEULE, Emily. La muerte en la poesia y en la arte de Grecia. México: Fondo de Cultura Economica, 1984, pp. 245-293.

VERNANT, Jean Pierre e VIDAL-NAQUET, Pierre. Mito e Tragédia na Grécia Antiga. São Paulo: Perspectiva, 1999.

VIDAL-NAQUET, P. Temps des dieux et temps des hommes. Essai sur quelques aspects de l'expérience temporelle chez les Grecs. In: Revue de I'histoire des religions, tome 157 n¹, 1960, p. 55-80.

WHITROW, Gerald. O tempo na História: concepções do tempo da pré-história aos nossos dias. Rio de Janeiro: Jorge Zahar, 1993.

\section{Imagens}

Imagem 1 Fonte: reprodução https://www.youtube.com/watchv=30Qz_etlhtg\&t=3590s Acessado em 31 dez. 2017

Imagem 2 Fonte: HAMMID, 1961, reprodução https://www.youtube.com/watchv=30Qz_e tlhtg\&t=3590s Acessado em 31 dez. 2017

Imagem 3 Fonte: HAMMID, 1961, reprodução https://www.youtube.com/watchv=30Qz_e tlhtg\&t=3590s Acessado em 31 dez. 2017

Imagem 4: Fonte: HAMMID, 1961, reprodução https://www.youtube.com/watchv=30Qz_e tlhtg\&t=3590s Acessado em 31 dez. 2017 